www.jmscr.igmpublication.org
Impact Factor 3.79

ISSN (e)-2347-176x

crossref DOI: http://dx.doi.org/10.18535/jmscr/v3i9.49 \footnotetext{
IGM Publication

Journal Of Medical Science And Clinical Research

An official Publication of IGM Publication

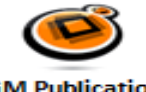
Jol

Journal Or Medical s
}

\title{
Performance of Urinary Liver Type Fatty Acid Binding Protein in Predicting Acute Kidney Injury in Post Cardiac Catheterization
}

\author{
Authors \\ Heba El-Shair1, Rania Swelem², Sherif Wagdy ${ }^{3}$ \\ ${ }^{1}$ Department of Internal Medicine, Faculty of Medicine, University of Alexandria \\ ${ }^{2}$ Department of Clinical Pathology, Faculty of Medicine, University of Alexandria \\ ${ }^{3}$ Department of Cardiology and Angilogy, Faculty of Medicine, University of Alexandria \\ Corresponding Author \\ Heba Elshair \\ Lecturer of Internal Medicine, Faculty of medicine, University of Alexandria, Egypt \\ Email: hebashair@gmail.com,Tel0201227466650
}

\begin{abstract}
Acute kidney injury (AKI) is a common medical problem and is significantly associated with increasing morbidity and mortality. Contrast media (CM) is increasingly used in diagnostic and interventional procedures which results in the rising incidence of iatrogenic renal function impairment caused by the exposure to CM, a condition known as contrast induced nephropathy (CIN). The fatty acid-binding proteins (FABPs) are small cytoplasmic proteins abundantly expressed in tissues with active fatty acid metabolism. Nine distinct types have been identified, with each named after the tissue in which they were first identified.The urinary excretion of L-FABP reflects stress of proximal tubular epithelial cells, correlating with severity of ischemic tubular injury. The performance of urinary L-FABP as an early detection marker of AKI has shown promise in various clinical settings. We aim in this study to assess the feasibility of urinary LFABP as very early marker of CI-AKI after cardiac catheterization in patient with stage 3or 4 CKD. A prospective study on 40 patients comparing urinary L-FABP excretion in group I (10 control subjects with normal renal functions) and group II (30 adult patients with chronic kidney disease stage 3or 4 and established AKI after elective cardiac catheterization at the Cardiology and Angilogy department. Measuring urinary $L-F A B P$ the day before and 6 hours after catheterization. There was a statistically significant positive correlation between $u-L F A B P / C r_{0}$ and $u-L F A B P / C r_{6}$ with $\mathrm{Cr}_{0}, \mathrm{Cr}_{24}, \mathrm{Cr}_{48}, \mathrm{Cr}_{72}$. There was a statistically significant negative correlation between eGFR and $u-L F A B P$.
\end{abstract}

Key words $U$-LFABP, acute kidney injury, cardiac catheterization

\section{INTRODUCTION}

Acute kidney injury (AKI) is a common medical problem; it is significantly associated with increasing morbidity and mortality. ${ }^{1}$. The progress in understanding molecular and biochemical mechanisms of AKI is complicated. Mortality rates in the ICU setting remain between $50-70 \%$, with a significant number of survivors exhibiting persistent evidence of renal dysfunction. ${ }^{2}$

Contrast media (CM) is increasingly used in diagnostic and interventional procedures which results in the rising incidence of iatrogenic renal function impairment caused by the exposure to $\mathrm{CM}$, condition known as contrast induced 
nephropathy (CIN). $11 \%$ of cases of hospitalacquired renal insufficiency are due to Radiographic interventional procedure which is the third most common cause of renal failure after renal hypo-perfusion and using of nephrotoxic medications. Among all procedures utilizing CM for diagnostic or therapeutic purposes, percutaneous coronary interventions (PCI) and coronary angiography are associated with the highest rates of CIN. ${ }^{(3)}$

Increased attention has been focused on identifying and addressing the progress in AKI research over the past 10 years. One problem is the continued reliance on markers for diagnosing AKI that do not reflect actual injury to renal cells, but the functional consequences of the injury. Serum creatinin ( $\mathrm{SCr}$ ) is considered a suboptimal marker that follows renal injury, levels are not reflective of the glomerular filtration rate (GFR) because of the influences of numbers of renal and non-renal factors. The dynamic relationship in AKI, between SCr and GFR inhibits the ability to accurately estimate the timing of renal injury and the severity of dysfunction after injury. A sudden fall in GFR to a constant low level causes a gradual increase in $\mathrm{SCr}$ until a new steady state between generation and excretion is achieved. Thus, the rate of increase in SCr after AKI is dependent on many factors, including the new GFR, rate of generation, rate of tubular secretion, and volume of distribution, so, severe injury and large changes in GFR may be associated with small, gradual changes in SCr during the first $48 \mathrm{~h}$ after injury, resulting in delayed diagnosis, underestimation of the degree of injury, and delayed intervention.

Intensive investigative efforts have led to the identification of a number of urinary proteins, including neutrophil gelatinase-associated lipocalin (NGAL), kidney injury molecule-1 (KIM-1), and interleukin-18 (IL-18), which have emerged as markers of AKI. The fatty acidbinding proteins (FABPs) are small cytoplasmic proteins abundantly expressed in tissues with active fatty acid metabolism. Nine distinct types have been identified, with each named after the tissue in which they were first identified. ${ }^{(4)}$ The primary function of FABPs seems to be the facilitation of long-chain fatty acid transport from the plasma membrane to sites for $\beta$-oxidation. ${ }^{8}$ In addition, FABPs may also have a role in the reduction of cellular oxidative stress, binding fatty acid oxidation products, and limiting the toxic effects of oxidative intermediates on cellular membranes. ${ }^{(5)}$

FABP is found to be expressed in the human renal proximal tubule epithelium, ${ }^{8}$ a nephron segment largely dependent on energy derived from fatty acid metabolism for normal cellular transport processes, So, urinary excretion of L-FABP reflects stress of proximal tubular epithelial cells, correlating with severity of ischemic tubular injury ${ }^{(6)}$

We aim in this study to assess the feasibility of urinary L-FABP as very early marker of CI-AKI after cardiac catheterization in patient with stage 3or 4 CKD.

\section{Subjects}

40 patients comparing urinary L-FABP excretion in group I (10 control subjects with normal renal functions) and group II (30 adult patients with chronic kidney disease stage 3 or 4 and established AKI after elective cardiac catheterization)Any patient with the following criteria will be excluded: older than 65, known acute renal failure, shock, intravenous administration of contrast within last 6 days ,liver disease ,using nephrotoxic drugs (aminoglycosides ,non steroidal anti-inflammatory drugs)

\section{Methods}

All of the cases in the study will be defined as AKI if associated with clinical confirmation buy decrease in urine output and laboratory by estimating GFR, and serum ceratinine before catheterization and 24, 48,72 hours post catheterization $^{(7)}$ Measuring urinary L-FABP the day before and 6 hours after catheterization ${ }^{(8)}$. All patients will be prescribed a hydration protocol 
prior to catheterization according to their cardiac conditions. An informed consent will be taken from all the participants in this study according to Helsinki declaration.

\section{Results}

Table (1) comparison between the studied groups according to baseline urea, creatinine and eGFR

\begin{tabular}{||c|c|c|c|c||}
\hline & $\begin{array}{c}\text { Group I } \\
(\mathbf{n = 1 0})\end{array}$ & $\begin{array}{c}\text { Group II } \\
(\mathbf{n}=\mathbf{3 0})\end{array}$ & $\mathbf{t}$ & $\mathbf{p}$ \\
\hline $\begin{array}{c}\text { Urea mg/dl } \\
\text { Min. - Max. }\end{array}$ & $18.0-50.0$ & $40.0-80.0$ & & \\
Mean \pm SD. & $39.90 \pm 9.95$ & $56.77 \pm 11.41$ & $\mathrm{t}=4.167^{*}$ & $<0.001^{*}$ \\
Median & 42.0 & 55.0 & & \\
\hline Creatinine mg/dl & & & & \\
Min. - Max. & $0.70-1.10$ & $1.0-1.50$ & & \\
Mean \pm SD. & $0.91 \pm 0.13$ & $1.32 \pm 0.12$ & $\mathrm{t}=8.921^{*}$ & $<0.001^{*}$ \\
Median & 0.89 & 1.35 & & \\
\hline eGFRml/min/1.73m & & & & \\
Min. - Max. & $75.20-103.70$ & $37.70-59.50$ & & \\
Mean \pm SD. & $90.62 \pm 10.29$ & $54.61 \pm 4.92$ \\
Median & 93.95 & 55.85 & $\mathrm{t}=10.668^{*}$ & $<0.001^{*}$ \\
\hline
\end{tabular}

Student t-test $\quad *$ : Statistically significant at $\mathrm{p} \leq 0.05$

There was a statistically significant difference between the two groups as regards serum urea,creatinin and eGFR $\mathrm{p}<0.001$.

Table (2) Comparison between the studied groups regarding the development of CI-AKI

\begin{tabular}{|c|c|c|c|c|c|c|}
\hline & \multicolumn{2}{|c|}{$\begin{array}{c}\text { Group I } \\
(n=10)\end{array}$} & \multicolumn{2}{|c|}{$\begin{array}{c}\text { Group II } \\
(\mathbf{n}=\mathbf{3 0})\end{array}$} & \multirow[t]{2}{*}{ Test of sig. } & \multirow[t]{2}{*}{$\mathbf{P}$} \\
\hline & No & $\%$ & No & $\%$ & & \\
\hline $\begin{array}{l}\text { No CI-AKI } \\
\text { CI-AKI }\end{array}$ & $\begin{array}{c}10 \\
0\end{array}$ & $\begin{array}{c}100.0 \\
0.0\end{array}$ & $\begin{array}{c}21 \\
9\end{array}$ & $\begin{array}{l}70.0 \\
30.0\end{array}$ & $\chi^{2}=3.871$ & ${ }^{\mathrm{FE}} \mathrm{p}=0.081$ \\
\hline
\end{tabular}


Table (3) comparison between the studied groups according to the type of CM used

\begin{tabular}{|c|c|c|c|c|c|c|}
\hline & \multicolumn{2}{|c|}{$\begin{array}{l}\text { Group I } \\
(\mathrm{no}=10)\end{array}$} & \multicolumn{2}{|c|}{$\begin{array}{l}\text { Group II } \\
(\mathrm{no}=30)\end{array}$} & \multirow{2}{*}{ Test of sig. } & \multirow{2}{*}{$\mathrm{P}$} \\
\hline & No & $\%$ & No & $\%$ & & \\
\hline \multicolumn{7}{|l|}{ Contrast Type } \\
\hline Iohexol & 10 & 100.0 & 9 & 30.0 & & \\
\hline Iopromide & 0 & 0.0 & 14 & 46.7 & $\chi^{2}=14.737^{*}$ & ${ }^{\mathrm{MC}} \mathrm{p}=0.001^{*}$ \\
\hline Iodixanol & 0 & 0.0 & 7 & 23.3 & & \\
\hline
\end{tabular}

$\chi^{2}$ : Value for Chi square testFE: Fisher Exact test*: Statistically significant at $p \leq 0.05$

There was a statistically significant difference between the two groups regarding the type of contrast media used $\mathrm{p}=0.001$

Table (4) comparison between the studied groups according to CM volume

\begin{tabular}{|c|c|c|c|c|c|c|}
\hline & \multicolumn{2}{|c|}{$\begin{array}{l}\text { Group } \\
(\text { no=10) }\end{array}$} & \multicolumn{2}{|c|}{ I $\begin{array}{l}\text { Group } \\
(\mathrm{no}=30)\end{array}$} & \multirow[t]{2}{*}{ Test of sig. } & \multirow{2}{*}{$\mathrm{p}$} \\
\hline & No & $\%$ & No & $\%$ & & \\
\hline \multicolumn{7}{|l|}{ CM Volume } \\
\hline Min. - Max. & \multicolumn{2}{|c|}{$110.0-280.0$} & \multicolumn{2}{|c|}{$100.0-250.0$} & & \\
\hline Mean \pm SD & \multicolumn{2}{|c|}{$154.50 \pm 60.48$} & \multicolumn{2}{|c|}{$146.80 \pm 34.93$} & $Z=0.579$ & 0.562 \\
\hline Median & \multicolumn{2}{|c|}{127.50} & \multicolumn{2}{|c|}{140.0} & & \\
\hline
\end{tabular}

$\mathrm{Z}$ : Z for Mann Whitney test *: Statistically significant at $\mathrm{p} \leq 0.05$

There was no statistically significant difference between the two study groups regarding CM volume $\mathrm{p}=0.562$.

Table (5) Comparison between the studied groups according to $\mathrm{u}-\mathrm{LFABP} / \mathrm{Cr}_{0}$ and $\mathrm{u}-\mathrm{LFABP} / \mathrm{Cr}_{6}$

\begin{tabular}{|c|c|c|c|c|}
\hline & $\begin{array}{l}\text { Group I } \\
(\mathbf{n}=\mathbf{1 0})\end{array}$ & $\begin{array}{l}\text { Group II } \\
\qquad(\mathbf{n}=\mathbf{3 0})\end{array}$ & $\mathbf{Z}$ & $\mathbf{p}$ \\
\hline \multicolumn{5}{|l|}{ u-LFABP/Cr ${ }_{0}(\mu \mathrm{g} / \mathrm{g})$} \\
\hline Min. - Max. & $0.39-2.17$ & $1.37-75.11$ & & \\
\hline Mean \pm SD & $1.22 \pm 0.61$ & $29.09 \pm 19.79$ & $4.467^{*}$ & $<0.001^{*}$ \\
\hline Median & 1.04 & 24.91 & & \\
\hline \multicolumn{5}{|l|}{ u-LFABP/Cr ${ }_{6}(\mu \mathrm{g} / \mathrm{g})$} \\
\hline Min. - Max. & $1.40-3.93$ & $3.37-399.68$ & & \\
\hline Mean \pm SD & $2.46 \pm 1.01$ & $118.68 \pm 110.58$ & $4.592^{*}$ & $<0.001^{*}$ \\
\hline Median & 2.04 & 84.86 & & \\
\hline
\end{tabular}




\begin{tabular}{|l|l|l|l||}
\hline $\mathbf{Z}_{\mathbf{1}}$ & $2.803^{*}$ & $4.782^{*}$ & \multirow{2}{*|}{$<0.001^{*}$} \\
\cline { 1 - 3 } $\mathbf{p}_{\mathbf{1}}$ & $0.005^{*}$ & \\
\hline
\end{tabular}

\section{$\mathrm{Z}$ : Z for Mann Whitney test}

$\mathrm{p}_{1}$ : $\mathrm{p}$ value for Wilcoxon signed ranks test for comparing between pre and post

*: Statistically significant at $\mathrm{p} \leq 0.05$

$\mathrm{Cr} 0$ creatinine measured before catheterization

C6 creatinine 6 hrs after catheterization

There was a statistically significant difference between $\mathrm{u}-\mathrm{LFABP} / \mathrm{Cr}_{0}$ between the two studied groups $\mathrm{p}<0.001$. There was a statistically significant difference between $\mathrm{u}-\mathrm{LFABP} / \mathrm{Cr}_{6}$ between the two studied groups $\mathrm{p}<0.001$

\section{Table (6) Correlation between eGFR with u-LFABP/Cr}

\begin{tabular}{|c|c|c|c|c|c|c|}
\hline & \multicolumn{6}{|l|}{ eGFR } \\
\hline & \multicolumn{2}{|c|}{ Group I } & \multicolumn{2}{|c|}{ Group II } & \multicolumn{2}{|c|}{ Total } \\
\hline & $\mathbf{r}_{\mathrm{s}}$ & $\mathbf{p}$ & $\mathbf{r}_{\mathrm{s}}$ & $\mathbf{p}$ & $\mathbf{r}_{\mathrm{s}}$ & $\mathbf{p}$ \\
\hline u-LFABP/Cr ${ }_{0}(\mu \mathrm{g} / \mathrm{g})$ & -0.236 & 0.511 & -0.499 & 0.060 & $-0.326^{*}$ & 0.040 \\
\hline u-LFABP/Cr ${ }_{6}(\mu \mathrm{g} / \mathrm{g})$ & -0.030 & 0.934 & -0.117 & 0.539 & $-0.496^{*}$ & 0.001 \\
\hline
\end{tabular}

$\mathrm{r}_{\mathrm{s}}$ : Spearman coefficient $*$ : Statistically significant at $\mathrm{p} \leq 0.05$

- There was a statistically significant negative correlation between eGFR and u-LFABP/Cr $\mathrm{C}_{0}$ in the two groups $\left(\mathrm{r}_{\mathrm{s}}=-0.326, \mathrm{p}=0.040\right)$

- there was a statistically significant negative correlation between eGFR and $\mathrm{u}-\mathrm{LFABP} / \mathrm{Cr}_{6}$ in the two groups $\left(\mathrm{r}_{\mathrm{s}}=-0.496, \mathrm{p}=0.001\right)$

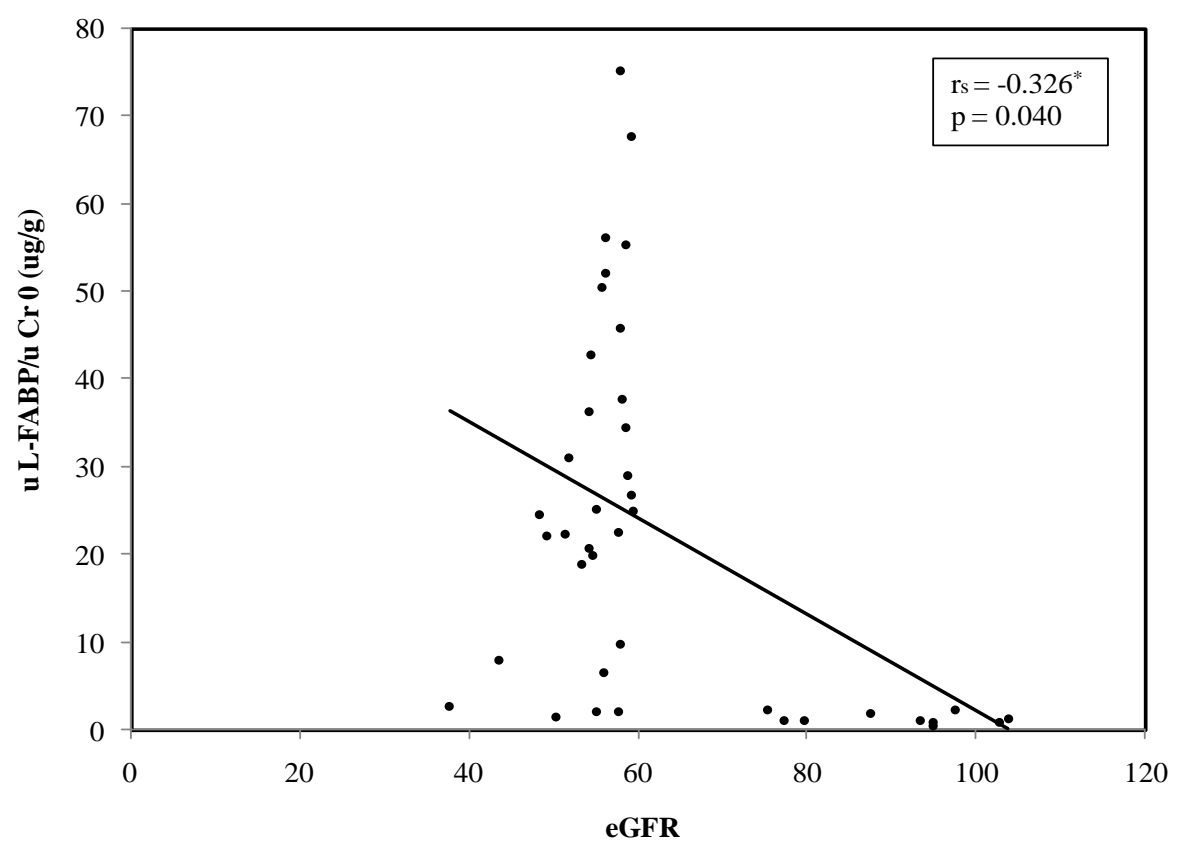

Figure (1): Correlation between eGFR with u-LFABP/Croin the study population 


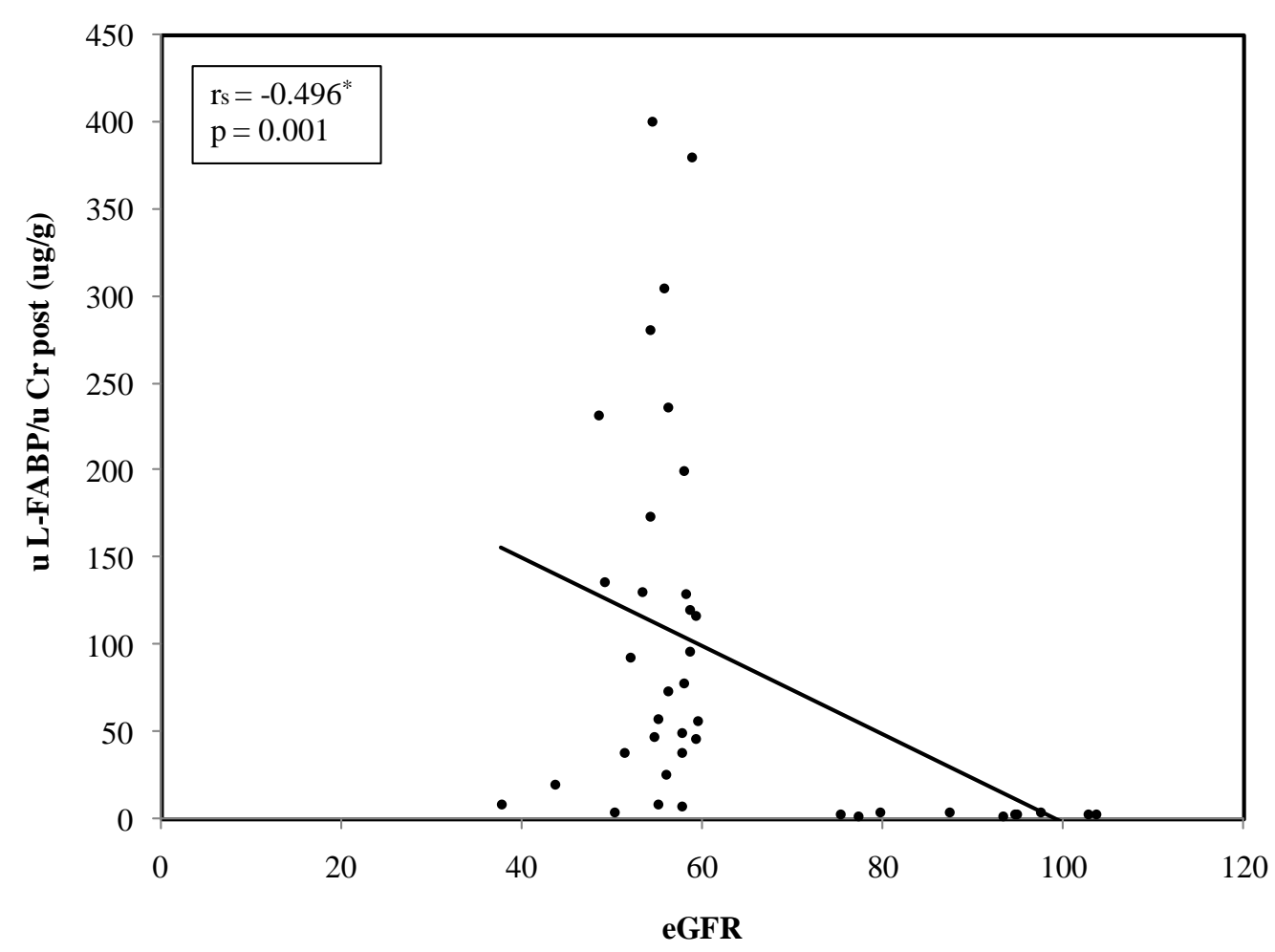

Figure (2): Correlation between eGFR with $\mathrm{u}-\mathrm{LFABP} / \mathrm{Cr}_{6}$ in the study population

Table (7): Correlation between u-LFABP/Cr, ${ }_{0}$ with Creatinine in the studied population

\begin{tabular}{|c|c|c|c|c|c|c|}
\hline & \multicolumn{6}{|c|}{$\mathrm{u}-\mathrm{LFABP} / \mathrm{Cr}_{\mathbf{0}}(\boldsymbol{\mu \mathrm { g }} / \mathrm{g})$} \\
\hline & \multicolumn{2}{|c|}{ Group I } & \multicolumn{2}{|c|}{ Group II } & \multicolumn{2}{|c|}{ Total } \\
\hline & $\mathbf{r}_{\mathrm{s}}$ & $\mathbf{p}$ & $\mathbf{r}_{\mathrm{s}}$ & $\mathbf{p}$ & $\mathbf{r}_{\mathrm{s}}$ & $\mathbf{p}$ \\
\hline $\mathrm{Cr}_{\mathbf{0}}$ & 0.189 & 0.601 & 0.027 & 0.888 & $0.509^{*}$ & 0.001 \\
\hline $\mathrm{Cr}_{24}$ & 0.178 & 0.623 & 0.013 & 0.944 & $0.532^{*}$ & $<0.001$ \\
\hline $\mathrm{Cr}_{48}$ & 0.092 & 0.801 & 0.093 & 0.625 & $0.490^{*}$ & 0.001 \\
\hline $\mathrm{Cr}_{72}$ & 0.086 & 0.812 & 0.127 & 0.502 & $0.464^{*}$ & 0.003 \\
\hline
\end{tabular}

$\mathrm{r}_{\mathrm{s}}$ : Spearman coefficient

*: Statistically significant at $\mathrm{p} \leq 0.05$

In both groups There was a statistically significant positive correlation between u-LFABP/Cr $\mathrm{Cr}_{0}, \mathrm{Cr}_{24}, \mathrm{Cr}_{48}$ and $\mathrm{Cr}_{72)}$ 


\section{JMSCR Vol||3||Issue||9||Page 7599-7610||September}

Table (8): Correlation between u-LFABP/Cr 6 with Serum Creatinine in the studied population

\begin{tabular}{|c|c|c|c|c|c|c|}
\hline & \multicolumn{6}{|c|}{$\mathrm{u}-\mathrm{LFABP} / \mathrm{Cr}_{6}(\boldsymbol{\mu g} / \mathrm{g})$} \\
\hline & \multicolumn{2}{|c|}{ Group I } & \multicolumn{2}{|c|}{ Group II } & \multicolumn{2}{|c|}{ Total } \\
\hline & $\mathbf{r}_{\mathrm{s}}$ & $\mathbf{p}$ & $\mathbf{r}_{\mathrm{s}}$ & $\mathbf{p}$ & $\mathbf{r}_{\mathrm{s}}$ & $\mathbf{p}$ \\
\hline $\mathrm{Cr}_{\mathbf{0}}$ & 0.311 & 0.382 & 0.163 & 0.390 & $0.452^{*}$ & 0.003 \\
\hline $\mathrm{Cr}_{24}$ & 0.331 & 0.350 & 0.038 & 0.843 & $0.524^{*}$ & 0.001 \\
\hline $\mathrm{Cr}_{48}$ & 0.306 & 0.390 & 0.241 & 0.199 & $0.638^{*}$ & $<0.001$ \\
\hline $\mathrm{Cr}_{72}$ & 0.117 & 0.747 & $0.395^{*}$ & 0.031 & $0.696^{*}$ & $<.0 .001$ \\
\hline
\end{tabular}

$\mathrm{r}_{\mathrm{s}}:$ Spearman coefficient

*: Statistically significant at $\mathrm{p} \leq 0.05$

In both groups There was a statistically significant positive correlation between $\mathrm{u}-\mathrm{LFABP} / \mathrm{Cr}_{6} \mathrm{Cr}_{0}, \mathrm{Cr}_{24}, \mathrm{Cr}_{48}$ and $\mathrm{Cr}_{72)}$

Table (9): Correlation between $\mathrm{u}-\mathrm{LFABP} / \mathrm{Cr}_{6}$ with $\mathrm{Cr}$ in the study population according to the development of CI-AKI

\begin{tabular}{|c|c|c|c|c|}
\hline & \multicolumn{4}{|c|}{ u-LFABP/Cr ${ }_{6}$} \\
\hline & \multicolumn{2}{|c|}{$\begin{array}{l}\text { Without CI-AKI } \\
(\mathbf{N = 3 1})\end{array}$} & \multicolumn{2}{|c|}{$\begin{array}{c}\text { With CI-AKI } \\
\qquad(\mathrm{N}=9)\end{array}$} \\
\hline & $\mathbf{r}_{\mathrm{s}}$ & $\mathbf{p}$ & $\mathbf{r}_{\mathrm{s}}$ & $\mathbf{p}$ \\
\hline $\mathrm{CrO}$ & 0.521 & 0.083 & 0.326 & 0.391 \\
\hline Cr24 & 0.539 & 0.102 & 0.407 & 0.277 \\
\hline Cr48 & 0.524 & 0.730 & 0.603 & 0.086 \\
\hline Cr72 & 0.504 & 0.064 & $0.596^{*}$ & $* 0.020$ \\
\hline
\end{tabular}

$\mathrm{r}_{\mathrm{s}}$ : Spearman coefficient $\quad *$ : Statistically significant at $\mathrm{p} \leq 0.05$

In Patients without CI-AKI ( $\mathrm{N}=31)$ There was a statistically non-significant positive correlation between uLFABP/Cr 6 and baseline $\mathrm{Cr}\left(\mathrm{Cr}_{0}, \mathrm{Cr}_{24}, \mathrm{Cr}_{48}\right.$ and $\left.\mathrm{Cr}_{72}\right)$.

In Patients with CI-AKI ( $\mathrm{N}=9$ ) There was a statistically significant positive correlation $\mathrm{u}-\mathrm{LFABP} / \mathrm{Cr}_{6}$ and $\mathrm{Cr}_{72}(\mathrm{r}=0.596, \mathrm{p}=0.020)$ 


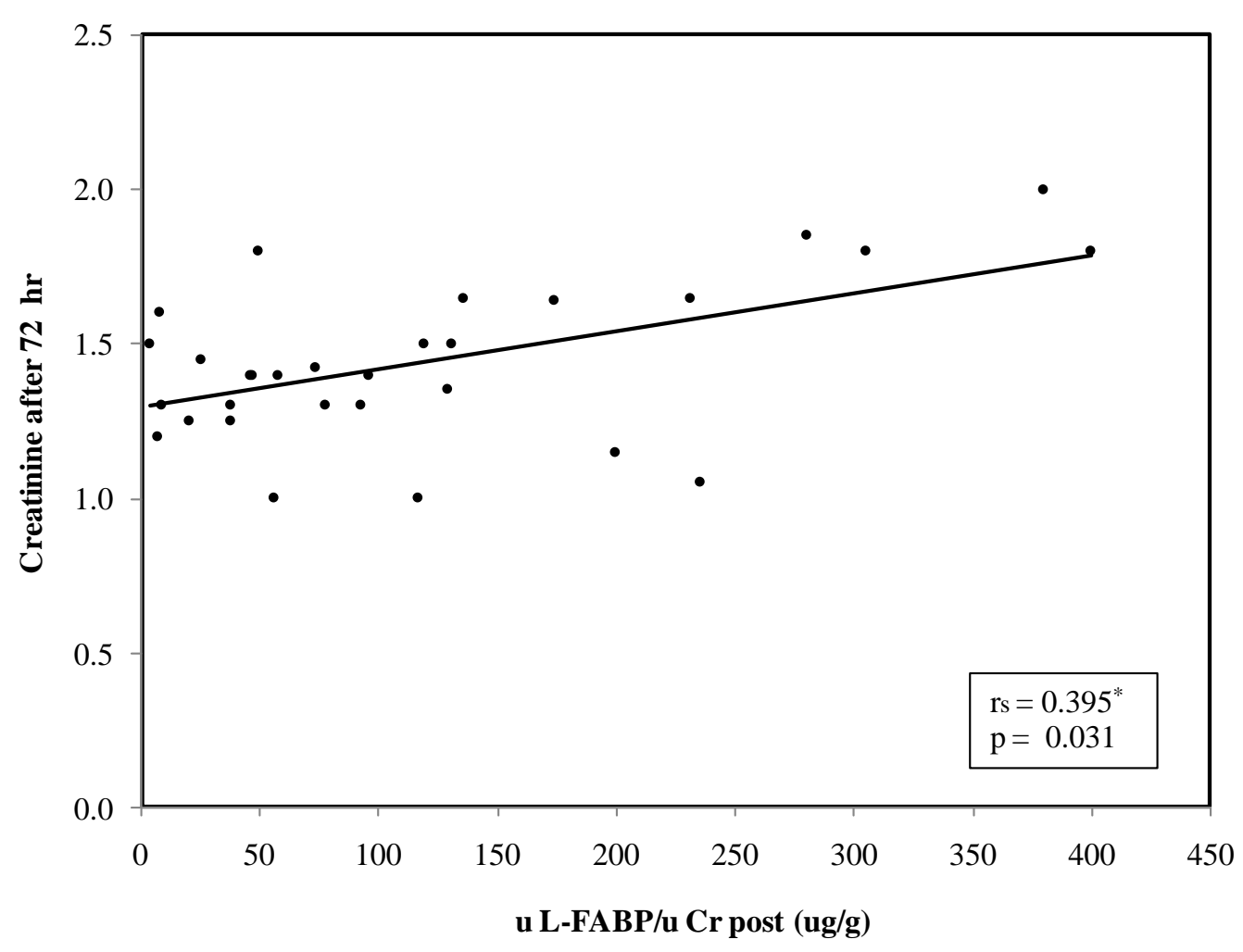

Figure (3): Correlation between u-LFABP/Cr 6 with $\mathrm{Cr}_{72} \mathrm{mg} / \mathrm{dl}$ in group II

Table (10): Relation between CI-AKI with CM type in group II

\begin{tabular}{|c|c|c|c|c|c|c|}
\hline & \multicolumn{4}{|c|}{ CI-AKI } & \multirow{3}{*}{$\chi^{2}$} & \multirow{3}{*}{${ }^{\mathbf{F E}} \mathbf{p}$} \\
\hline & \multicolumn{2}{|c|}{$\begin{array}{c}\text { No } \\
(\mathbf{n}=21)\end{array}$} & \multicolumn{2}{|c|}{$\begin{array}{c}\text { Yes } \\
(\mathbf{n}=9)\end{array}$} & & \\
\hline & No. & $\%$ & No. & $\%$ & & \\
\hline CM Type & & & & & & \\
\hline Iohexol (n=9) & 3 & 14.3 & 6 & 66.7 & $8.231^{*}$ & $0.008^{*}$ \\
\hline Iopromide $(n=14)$ & 11 & 52.4 & 3 & 33.3 & 0.716 & 0.456 \\
\hline Iodixanol $(\mathrm{n}=7)$ & 7 & 33.3 & 0 & 0.0 & 3.913 & 0.071 \\
\hline
\end{tabular}

$\chi^{2}$ : Value for Chi square test

MC: Monte Carlo test

FE: Fisher Exact test

*: Statistically significant at $\mathrm{p} \leq 0.05$

There was a statistically significant relation between CI-AKI and Iohexol administration $\mathrm{p}=0.008$ 
Table (11): Correlation between $\mathrm{u}-\mathrm{LFABP} / \mathrm{Cr}_{6}$ with $\mathrm{CM}$ volume in the study population according to the development of CI-AKI

\begin{tabular}{|l|c|c|c|c|}
\hline \multirow{2}{*}{} & \multicolumn{2}{|l|}{ u-LFABP/Cr } \\
\cline { 2 - 5 } & \multicolumn{2}{|c|}{$\begin{array}{c}\text { Without CI-AKI } \\
(\mathbf{N}=\mathbf{3 1})\end{array}$} & \multicolumn{2}{|c|}{$\begin{array}{c}\text { With CI-AKI } \\
\text { (N=9) }\end{array}$} \\
\cline { 2 - 5 } & $\mathbf{r}_{\mathrm{s}}$ & $\mathbf{p}$ & $\mathbf{r}_{\mathrm{s}}$ & $\mathbf{p}$ \\
\hline CM volume & 0.042 & 0.823 & 0.067 & 0.865 \\
\hline
\end{tabular}

$\mathrm{r}_{\mathrm{s}}$ : Spearman coefficient

*: Statistically significant at $\mathrm{p} \leq 0.05$

In Patients with and without CI-AKI There was statistically non-significant positive correlation between CM volume and $\mathrm{u}-\mathrm{LFABP} / \mathrm{Cr}_{6}$

\section{Discussion}

Over the past several decades, numerous advances have been made in the understanding of the pathophysiological mechanisms implicated in AKI and the compensatory mechanisms involved in renal 5 recovery. ${ }^{(9)}$ Reliance on $\mathrm{SCr}$ as a marker of renal injury has contributed to the slow translation of basic science discovery to therapeutically effective approaches in clinical practice.

Recent reports have established urinary L-FABP as a useful biomarker in clinical models of ischemic AKI. Yamamoto et al. ${ }^{(10)}$ reported that urinary L-FABP levels correlated well with the ischemic time of the transplanted kidney and with the length of hospital stay in human living relateddonor renal transplant recipients. also, Portilla et $a l{ }^{(11)}$ who measured serum and urine L-FABP in patients undergoing cardiac surgery. There was a significant increase of urinary L-FABP levels $4 \mathrm{~h}$ after the surgery, where as serum L-FABP levels did not begin to increase until $12 \mathrm{~h}$ postoperatively. These observations support the concept that the human urinary L-FABP level is mostly determined by proximal tubule injury, rather than extrarenal production (from liver injury, or systemic inflammation associated with cardiopulmonary bypass or sepsis), they found that levels at the $4 \mathrm{~h}$ post-operative time point were predictive of those who subsequently developed AKI. These findings agreed the results of the present study which showed that there was positive statistically significant difference in $\mathrm{u}$ $\mathrm{LFABP} / \mathrm{Cr}_{0}$ between the two studied groups $\mathrm{p}<0.001$ and there was a statistically significant difference between $\mathrm{u}-\mathrm{LFABP} / \mathrm{Cr}_{6}$ between the two studied groups $\mathrm{p}<0.001$ indicating that there is actual increase of u-LFABP among CI-AKI patients.

In addition, Nakamura et al. ${ }^{(12)}$ conducted a study on 66 patients undergoing non-emergency coronary angiography who had a serum creatinine level greater than $1.2 \mathrm{mg} / \mathrm{dl}(>106 \mu \mathrm{mol} / \mathrm{l})$ and less than $2.5 \mathrm{mg} / \mathrm{dl} \quad(<221 \mu \mathrm{mol} / \mathrm{l})$ and 30 healthy volunteers reported that Urinary L-FABP levels were detectable before angiography and predicted those who developed contrast medium-induced nephropathy. After 14 days, serum creatinine levels returned to normal and L-FABP levels remained high.

Michael A. Ferguson et al (13) evaluated a heterogeneous group of adult patients and showed significantly elevated urinary L-FABP levels in established AKI of varying etiology, including acute tubular necrosis, sepsis, and nephrotoxin exposure. They Showed the comparative value of multiple biomarkers in the diagnosis and prognosis of AKI. ${ }^{(14)}$ The diagnostic ability of 
urinary L-FABP in hospitalized patients was very good, comparable to other well-described biomarkers of AKI, including NGAL , KIM-1, NAG L, and statistically better than IL-18 .Considerable overlap of urinary L-FABP values was noted, particularly among AKI patients and ICU controls without AKI. There are at least two explanations for this phenomenon. It is possible that increased urinary L-FABP levels in acutely ill ICU patients without a diagnosis of AKI are indicative of some other systemic process and therefore reflect decreased specificity for AKI. Alternatively, it is possible to be due to subtle renal injury that does not result in increased $\mathrm{SCr}$ and therefore reflect increased sensitivity for AKI. Paweena S.,et a ${ }^{(14)}$ summarize the results of all the published studies that have examined the performance characteristics of urinary biomarker, L-FABP. Of the 12 identified cohort studies of patients at-risk for AKI, only 7 could be metaanalyzed for diagnosis of AKI, whereby urinary L-FABP displayed good performance characteristics with high sensitivity and specificity, especially among patients undergoing cardiac surgery at risk for development of AKI. Paweena S.,et al ${ }^{(14)}$ subgroup analysis of patients undergoing cardiac surgery, found that 4-hour post-operative time-point offered good biomarker performance. In the present study measuring urinary L-FABP was 6 hours post cardiac catheterization. There was a statistically significant positive correlation between $\mathrm{u}$ $\mathrm{LFABP} / \mathrm{Cr}_{0}$ and $\mathrm{Cr}_{0}, \mathrm{Cr}_{24}, \mathrm{Cr}_{48}, \mathrm{Cr}_{72)}$ and there was a statistically significant positive correlation between u-LFABP/Cr 6 and $\left(\mathrm{Cr}_{0}, \mathrm{Cr}_{24}, \mathrm{Cr}_{48}, \mathrm{Cr}_{72}\right)$.

In the current study there was a statistically significant negative correlation between eGFR and $\mathrm{u}-\mathrm{LFABP} / \mathrm{Cr}_{0}$ in the studied population $\left(\mathrm{r}_{\mathrm{s}}=-\right.$ $0.326, \mathrm{p}=0.040$ ) and there was also a statistically significant negative correlation between eGFR and $\mathrm{u}-\mathrm{LFABP} / \mathrm{Cr}_{6}$ in the studied population $\left(\mathrm{r}_{\mathrm{s}}=-\right.$ $0.496, \mathrm{p}=0.001$ ) these findings agreed the aforementioned studies showing that urinary LFABP displayed good performance characteristics especially among patients undergoing cardiac catheterization at risk for development of
AKI.Also these findings were confirmed by having a statistically non-significant positive correlation between u-LFABP/Cr $\mathrm{r}_{0}$ and baseline $\mathrm{Cr}$ $\left(\mathrm{Cr}_{0}, \mathrm{Cr}_{24}, \mathrm{Cr}_{48}\right)$ and statistically significant positive correlation between $\mathrm{u}-\mathrm{LFABP} / \mathrm{Cr}_{6}$ and $\mathrm{Cr}_{72}(\mathrm{r}=0.596, \mathrm{p}=0.020)$.

Clinical Evaluation trial indicated that in $80 \%$ of CIN cases serum creatinine started to rise within the first $24 \mathrm{~h}$ post-CM exposure, and most patients who progressed to serious renal failure had a rise in serum creatinine within this time. The same study showed that patients with less than $0.5 \mathrm{mg} / \mathrm{dl}$ rise in serum creatinine within the first $24 \mathrm{~h}$ were unlikely to have any clinically form of CIN (15)

Controversy exists whether the use of different contrast agents is of any benefit in diminishing the risk of CIN. In studies by Katholi et al. ${ }^{16}$ and by Harris et al. ${ }^{17}$ the decrease in creatinine clearance was more pronounced and lasted longer in the group that received high-osmolality CM compared to the arm exposed to low-osmolality CM. On the contrary, Schwab et al. ${ }^{18}$ did not show any significant differences in nephrotoxic effect between several studied CM.

The findings in the present study were in accordance with studies by Katholi et al. ${ }^{16}$ and by Harris et al. ${ }^{17}$ There was a statistically significant correlation between CI-AKI and Iohexol administration $\mathrm{p}=0.008$ and these findings were not found with the other two types of contrast (Iopromide, Iodixanol )

The osmolality of iohexol( Omnipaque) ranges from (322-844)mOsm/kg 1-3 times that of blood plasma .Iopromide( Ultravist) is a low osmolar, non-ionic contrast agent $(774 \mathrm{mOsm} / \mathrm{kg})$

Iodixanol (Visipaque ) is the only iso-osmolar contrast agent, with an osmolality of 290 $\mathrm{mOsm} / \mathrm{kg}$, the same as blood.

Contrast Medium Volume and dose may alter the risk of contrast-induced AKI. Generally, a volume of contrast medium of no more than $100 \mathrm{~mL}$ is preferable for patients with an eGFR lower than $60 \mathrm{~mL} / \mathrm{min} / 1.73 \mathrm{~m}$. A volume limit of $5 \mathrm{~mL} / \mathrm{kg}$ body weight normalized to the serum creatinine 
concentration has also been proposed as a threshold for contrast-induced AKI in patients with CKD. The ratio of contrast medium volume to $\mathrm{CrCl}$ has been suggested to be a more accurate predictor of AKI than other factors; a ratio higher than 3.7 is associated with increased risk. This ratio could be applied prospectively to determine the maximum contrast medium volume that can be administered without substantially increasing the risk of AKI. ${ }^{19}$

In the present study patients with CI-AKI showed statistically non-significant positive correlation between $\mathrm{CM}$ volume and $\mathrm{u}-\mathrm{LFABP} / \mathrm{Cr}_{6}$ $(\mathrm{r}=0.067, \mathrm{p}=0.865)$, this finding may be attributed to small sample sized.

\section{References}

1. Liangos O, Wald R, O'Bell JW, et al. Epidemiology and outcomes of acute renal failure in hospitalized patients: a national survery. Clin J Am Soc Nephrol. 2006;1:43-51.

2. Uchino S, Kellum JA, Bellomo R, et al. Acute renal failure in critically ill patients: a multinational, multicenter study. JAMA. 2005;294:813-818.

3. Nash K, Hafeez A, Hou S. Hospitalacquired renal insufficiency. Am J Kidney Dis 2002; 39: 930-936.

4. Pelsers MM, Hermens WT, Glatz JF. Fatty acid-binding proteins as plasma markers of tissue injury. Clin Chim Acta. 2005;352:15-35.

5. Wang G, Gong $Y$, Anderson J, et al. Antioxidative function of L-FABP in LFABP stably transfected Chang liver cells. Hepatology. 2005;42:871-879.

6. Devarajan P. Biomarkers for the early detection of acute kidney injury. Curr Opin Pediatr. 2011 Apr;23(2):194-200.

7. Kratz A,Ferraro M ,Sluss PM et al,laboratory reference value . N Engl J Med 2004;351:2461.

8. Noiri E,Tsukahara H.parameters of measurements of oxidative stress in diabetes mellitus :applicability of ELISA for clinical evaluation $\mathrm{J}$ investing Med 2005;4167-75.

9. Schrier RW, Wang W, Poole B, et al. Acute renal failure: definitions, diagnosis, pathogenesis, and therapy. J Clin Invest. 2004;114:5-14.

10. Yamamoto T, Noiri E, Ono Y, et al. Renal L-type fatty acid binding protein in acute ischemic injury. J Am Soc Nephrol. 2007;18:2894-2902.

11. Portilla D, Dent C, Sugaya T, et al. Liver fatty acid-binding protein as a biomarker of acute kidney injury after cardiac surgery. Kidney Int. 2007;73:465-472.

12. Nakamura T, Sugaya T, Node K, et al. Urinary excretion of liver-type fatty acidbinding protein in contrast mediuminduced nephropathy. Am J Kidney Dis. 2006;47:439-444.

13. Michael A. Ferguson, Vishal S. et al. Urinary liver-type fatty acid-binding protein predicts adverse outcomes in acute kidney injury Kidney Int. 2010 Apr; 77(8): 708-714.

14. Paweena Susantitaphong, Monchai Siribamrungwong, Kent Doi, et al.Performance of Urinary Liver-Type Fatty Acid-Binding Protein in Acute Kidney Injury: A Meta-analysis Am J Kidney Dis. 2013 Mar; 61(3): 430-439.

15. Stevens MA, McCullough PA, Tobin KJ et al. A prospective randomized trial of prevention measures in patients at high risk for contrast nephropathy: results of the P.R.I.N.C.E. Study: Prevention of Radiocontrast Induced Nephropathy Clinical Evaluation. $J \quad A m$ Coll Cardiol 1999; 33: 403-411.

16. Katholi RE, Taylor GJ, Woods WT et al. Nephrotoxicity of nonionic low-osmolarity versus ionic high-osmolarity contrast media: a prospective double-blind randomized comparison in human beings. Radiology 1993;186: 183-187.

17. Harris KG, Smith TP, Cragg AH, et al. Nephrotoxicity from contrast material in 
renal insufficiency: ionic versus nonionic agents. Radiology1991; 179: 849-852.

18. Schwab SJ, Hlatky MA, Pieper KS et al. Contrast nephrotoxicity: a randomized controlled trial of a nonionic and an ionic radiographic contrast agent. $N$ Engl $J$ Med 1989; 320: 149-153.

19. Laskey WK, Jenkins C, Selzer F, et al. NHLBI Dynamic Registry Investigators Volume-to-creatinine clearance ratio: pharmacokinetically based risk factor for prediction of early creatinine increase after percutaneous coronary intervention. $J \mathrm{Am}$ Coll Cardiol. 2007August;50(7):584-590 . 